\title{
Selection and Incentives in Contests: Evidence from Horse Racing
}

\author{
Alasdair Brown* \\ Fuyu Yang ${ }^{\dagger}$ \\ University of East Anglia University of East Anglia
}

February 8, 2016

\begin{abstract}
The designer of internal labour market promotion contests must balance the need to select the best candidate with the need to provide incentives for all candidates. We use an extensive data-set from horse racing - where there is abundant variation in contest design features - to analyse if there are particular features that help to achieve these two objectives. We find that contests with higher prize money, and fewer participants, are the most successful at achieving the dual remit of selection and incentives.
\end{abstract}

JEL Classification: C3, D72, J24

Keywords: contests, relative performance, selection, quitting Word count (including references, tables and captions): 2,179 words

${ }^{*}$ Corresponding Author. School of Economics, University of East Anglia, Norwich NR4 7TJ, U.K.. Email: alasdair.brown@uea.ac.uk

${ }^{\dagger}$ School of Economics, University of East Anglia, Norwich NR4 7TJ, U.K.. Email: fuyu.yang@uea.ac.uk 


\section{Introduction}

Competition for promotion within a firm has often been likened to a contest, where all employees exert effort but only some receive a prize (Konrad, 2009). In these contests a trade-off exists between promoting the most able employee with high probability, and yet also giving incentives for weaker employees to continue exerting effort until the promotion contest is decided (Tsoulouhas et al., 2007, Höchtl et al., 2011). If the contest is too heavily skewed towards stronger candidates, then weaker candidates will cease to exert effort, and their potential output will be lost. Level the playing field, however, and the firm may be left with inferior employees in senior positions.

In this paper we exploit the abundant variation in contest design features in horse racing to establish whether any particular design feature can both help to select the best and yet ensure that all participants are sufficiently incentivized until the end of the contest. Horse races vary in terms of winner incentives (prize money), difficulty (distance, hurdles), requisite quality (class), and the number of participants (runners). Just as important as this variation in design features, we have clean measures of both selection and incentives. We measure selection by the frequency with which the favourite - more often than not the best horse in the race - won the race. We measure incentives by the frequency with which horses were pulled-up (i.e. quit) before the race was completed. As injured horses, or those involved in an accident or a fall, are classified separately, we can assume that those that 'pull-up' only do so because they have drifted out of contention and have given up on victory. A lagging horse (and jockey) quitting a race before the finishing line is, according to our analogy, akin to a discouraged employee giving up on future promotions and deciding to down tools.

Our results suggest that features which are successful in eliciting continued effort from all runners are, in the main, less successful in ensuring that the best horse prevails. The exceptions are 1) races with relatively high prize money for the winner, and 2) races with fewer participants. As races with fewer participants have arguably discouraged weaker participants from even entering the race, only high stakes races appear to fit the dual remit of selection and incentives.

Horse racing has been used previously in the study of contest design features. For example, Lynch (2005) shows that a steeper prize structure - where the difference in prize money be- 
tween first and second, for example, is greater — leads to quicker running times and implicitly more effort. Coffey and Maloney (2010) use horse and dog racing data to disentangle the component of effort that is caused by incentives, from the component of effort that is observed because of higher quality selection. Horse racing is particularly well-suited to the objectives of our study for three reasons. Firstly, it has perhaps the greatest variation in contest design features of any sport. There is almost a continuum of prizes, distances, classes, and runners to be observed in horse racing, plus clear differences between flat and jump racing. Secondly, in common with most sports but in contrast with most labour market environments, it is possible to ex-ante identify the most able competitor in horse racing by using the prices observed in the pre-race betting market. Thirdly, in contrast to most sports and labour market environments, we have a remarkably clean measure of low effort. The 28,382 (5.1\%) horses that pull-up in our sample have, by definition, ceased to exert any more effort in the pursuit of victory.

The trade-off between selection and incentives in contests has been examined experimentally by Höchtl et al. (2011). Specifically, the authors examined how the ex-ante closeness of the contest affected the two objectives. Our paper is, however, the first field evidence on this subject involving professionals, and also considers the effects of a broader range of natural contest features. Other than this work, selection and incentives have generally been considered separately in the literature. For example, designing contests or tournaments so that they are effective in selecting the best competitor has been considered theoretically by Hvide and Kristiansen (2003), Rvykin and Ortmann (2008), and Rvykin (2010), and empirically by Harbraugh and Klumpp (2005) and Klumpp and Polborn (2006). Regarding incentives, it has been shown theoretically (Lazear and Rosen, 1981), and in the field (Sunde, 2009, Brown, 2011, Franke, 2012, and Genakos and Pagliero, 2012) that uneven contests elicit less effort from weaker participants. As we stated, this is the first analysis to jointly establish whether a range of contest features can help in the achievement of both selection and incentive goals.

Our work also builds on a more general theme of trade-offs in contest design features. For example, Boudreau et al. (2011) identify a trade-off in innovation contests in computer software development. On the one hand, adding competitors to the contest increases the probability of achieving an 'extreme-value solution' to the particular innovation problem. On the other hand, for less difficult innovation contests, the addition of competitors discourages 
others and leads to lower effort and investment. In our paper we empirically identify a comparable trade-off, but show that there is the possibility that certain features can achieve the dual aims of the contest designer.

\section{Data}

We collected data on 54,090 U.K. horse races run between 1st January 2005 and the 31st December 2010. These races included a total of 557,296 runners. This data was obtained from Betwise, a U.K. based betting information firm. Of the 54,090 races in our sample, $29,806(55.1 \%)$ were handicap races. In such races a handicapper assigns different weights to each horse, with the intention of giving every horse the same chance of victory. In addition, $18,274(33.8 \%)$ of the races in our sample were jump races, where horses must clear a succession of hurdles. Races also vary in terms of distance (from 1,100 yards to 7,920 yards) and in terms of prize money for the winner (from 0 to 1 million GDP). Finally, races are graded by class, with 1 the most prestigious (and most difficult to enter), and 7 the lowest.

Our analysis can be summarised in just two regressions, the results of which are displayed in Table 1. In the first regression, the dependent variable is an indicator equalling 1 if the favourite (i.e. the horse with the shortest win odds in the race) ultimately won the race. This is regressed on the race design features described above, plus the age and squared age of the favourite to control for physiological variations over the horse's career. If a race has a joint favourite, we include both horses, though our results are robust to discarding all but the first favourite as decided by alphabetical order. This first regression is estimated using a logit specification, with heteroskedasticity-consistent standard errors. In our second regression, the dependent variable is an indicator equalling 1 if the horse in question pulled-up, i.e. quit before the end of the race. The explanatory variables are the same as the first regression, but this time we include all 557,296 runners in the sample. A logit specification is again used, but standard errors are now clustered at the race level in addition to being heteroskedasticity-consistent.

We are looking for race design features which correlate with a higher frequency of the favourite winning (i.e. selection attributes), and also correlate with a lower frequency of dropouts (i.e. incentives for all). For this dual remit to be satisfied, we require that the 
estimated coefficients of the two regressions differ in their sign. The majority of the design features are suitable for one objective, but not the other. For example, handicapping levels the playing field and ensures continued effort from more horses (as witnessed by lower dropout rates), but the best horse (if indeed the favourite is the best horse in a handicap) wins less often. Similarly, jump races — which are arguably more difficult and hazardous — are proficient at weeding out weaker horses (the favourite wins more often), but horses are much more likely to pull-up in these races.

There are two design features which appear to satisfy the selection and incentives criteria. These are 1) the prize money awarded to the winner, and 2) the number of horses in the race. Specifically, those races with higher stakes, and fewer competitors, see the favourite win more often, and yet are still afflicted by fewer mid-race dropouts. Of course, these results could be driven by a selection bias. Most obviously, a race with few competitors has arguably already discouraged weaker horses: after all, a horse that does not participate cannot be observed falling behind and then quitting. A similar, albeit more subtle, effect may be at play in high stakes races. Consider a high stakes race that attracts stronger horses. The presence of these horses deters weaker horses from entering. Therefore, we do not observe a high dropout rate, since the other horses have not even taken part. Crucially, however, the proficiency of high stakes races in both selection and incentives criteria remains even after we control for the number of entrants in these races. Our intuition is that high stakes races attract and motivate the best, and, because of the size of the prize at stake, still manage to keep weaker competitors interested, even when their chances of victory are negligible.

One remaining concern is an omitted variable bias. Although we have a range of observables to use as controls, there may be unobservable factors, correlated with win prize money, which are predominantly driving the two results. Although the success of prize money in the selection and incentives criteria is intuitively sensible, further work in controlled laboratory conditions could see whether the effect holds once unobservable variation is eliminated. 


\begin{tabular}{|c|c|c|}
\hline \multirow[t]{2}{*}{ Dependent Variable: } & Favourite Won Race & Pulled Up \\
\hline & 1 & 2 \\
\hline \multirow[t]{2}{*}{ Intercept } & 0.105 & $-8.629 * * *$ \\
\hline & $(.064)$ & $(.081)$ \\
\hline \multirow[t]{2}{*}{ Handicap Indicator } & $-0.494^{* * *}$ & $-0.135^{* * *}$ \\
\hline & $(.019)$ & $(.017)$ \\
\hline \multirow[t]{2}{*}{ Jump Race Indicator } & $0.187^{* * *}$ & $3.166^{* * *}$ \\
\hline & $(.039)$ & $(.049)$ \\
\hline \multirow[t]{2}{*}{ Distance (000s of yards) } & 0.017 & $0.505^{* * *}$ \\
\hline & $(.013)$ & $(.011)$ \\
\hline \multirow[t]{2}{*}{ No of Horses in Race } & $-0.073^{* * *}$ & $0.042^{* * *}$ \\
\hline & $(.002)$ & $(.002)$ \\
\hline \multirow[t]{2}{*}{ Class } & $0.041^{* * *}$ & $0.165^{* * *}$ \\
\hline & $(.007)$ & $(.007)$ \\
\hline \multirow[t]{2}{*}{ Win Prize (000s of GBP) } & $0.0007^{*}$ & $-0.002^{* * *}$ \\
\hline & $(.0003)$ & $(.0002)$ \\
\hline \multirow[t]{2}{*}{ Age } & -0.035 & $0.067^{* * *}$ \\
\hline & $(.02)$ & $(.018)$ \\
\hline \multirow[t]{2}{*}{$A g e^{2}$} & -0.0009 & -0.001 \\
\hline & $(.001)$ & $(.001)$ \\
\hline \multirow{2}{*}{$\begin{array}{l}\text { No. of Observations } \\
\text { Pseudo } R^{2}\end{array}$} & 59,494 & 557,296 \\
\hline & 0.026 & 0.279 \\
\hline
\end{tabular}

Regressions to establish whether certain types of contests are able to select the best candidate with high probability, and yet also incentivize continued participation by all contestants. In our first regression we regress an indicator variable, equalling 1 if the favourite (i.e. the best horse) won the race, on a variety of contest design features. (We include all joint favourites in this regression). In our second regression we include all runners (not just the favourite) and regress an indicator, equalling 1 if the horse was pulled-up mid-race (i.e. quit), on the same contest design features. Logit specifications are used in both regressions. Standard errors (displayed in parentheses) are heteroskedasticity-consistent in both regressions, and are clustered at the race level $(\mathrm{N}=54,090)$ in regression $2 . .^{*}, * *$, and $* * *$ indicates significance at the $10 \%, 5 \%, 1 \%$ and $0.1 \%$ level respectively. 


\section{References}

- Boudreau, K., J., Lacetera, N., Lakhani, K., R., (2011). Incentives and Problem Uncertainty in Innovation Contests: An Empirical Analysis. Management Science, 57, 843-863.

- Brown, J., (2011). Quitters Never Win: The (Adverse) Incentive Effects of Competing with Superstars. Journal of Political Economy, 119, 982-1013.

- Coffey, B., Maloney, M., T., (2010). The Thrill of Victory: Measuring the Incentive to Win. Journal of Labor Economics, 28, 87-112.

- Franke, J., (2012). The Incentive Effects of Levelling the Playing Field - An Empirical Analysis of Amateur Golf Tournaments, Applied Economics, 44, 1193-1200.

- Genakos, C., Pagliero, M., (2012). Interim Rank, Risk-Taking, and Performance in Dynamic Tournaments. Journal of Political Economy, 120, 782-813.

- Harbaugh, R., Klumpp, T., (2005). Early Round Upsets And Championship Blowouts. Economic Inquiry, 43, 316-329.

- Höchtl, W., Kerschbamer, Stracke, R., Sunde, U., (2011). Incentives vs. Selection in Promotion Tournaments: Can a Designer Kill Two Birds with One Stone? IZA Discussion Paper, no. 5755.

- Hvide, H., K., Kristiansen, E., G., (2003). Risk Taking in Selection Contests. Games and Economic Behavior, 42, 172-179.

- Klumpp, T., Polborn, M., K., (2006). Primaries and the New Hampshire Effect. Journal of Public Economics, 90, 1073-1114.

- Konrad, K., A., (2009). Strategy and Dynamics in Contests: London School of Economics Perspectives in Economic Analysis. Oxford University Press.

- Lazear, E., P., Rosen, S., (1981). Rank Order Tournaments as Optimum Labor Contracts. Journal of Political Economy, 89, 841-864. 
- Lynch, J., G., (2005). The Effort Effects of Prizes in the Second Half of Tournaments. Journal of Economic Behavior and Organization, 57, 115-129.

- Ryvkin, D., (2010). The Selection Efficiency of Tournaments. European Journal of Operational Research, 206, 667-675.

- Ryvkin, D., Ortmann, A., (2008). The Predictive Power of Three Prominent Tournament Formats. Management Science, 54, 492-504.

- Sunde, U., (2009). Heterogeneity and Performance in Tournaments: A Test for Incentive Effects Using Professional Tennis Data. Applied Economics, 41, 3199-3208.

- Tsoulouhas, T., Knoeber, C., R., Agrawal, A., (2007). Contests to Become CEO: Incentives, Selection and Handicaps. Economic Theory, 30, 195-221. 